\title{
Potential of a simple solid-phase extraction method coupled to analytical and bioanalytical methods for an improved determination of microcystins in algal samples
}

\author{
Yi-Min Chen ${ }^{\mathrm{a}, \mathrm{d}, *}$, Tzong-Huei Lee ${ }^{\mathrm{b}}$, Shyh-Jye Lee ${ }^{\mathrm{c}}$, Jian-Zhi Lin ${ }^{\mathrm{d}}$, \\ Rang Huang ${ }^{\mathrm{a}}$, Hong-Nong Chou ${ }^{\mathrm{d}, *}$ \\ a Institute of Oceanography, National Taiwan University, Taipei 106, Taiwan, ROC \\ ${ }^{\mathrm{b}}$ Graduate Institute of Pharmacognosy Science, Taipei Medical University, Taipei 110, Taiwan, ROC \\ ${ }^{\mathrm{c}}$ Institute of Zoology, National Taiwan University, Taipei 106, Taiwan, ROC \\ ${ }^{\mathrm{d}}$ Institute of, Fisheries Science, National Taiwan University, Taipei 106, Taiwan, ROC
}

Received 15 February 2006; accepted 7 July 2006

Available online 4 August 2006

\begin{abstract}
Artemia assays and protein phosphatase assays are commonly used for the screening of microcystins (MCs) in algal samples instead of the standard mouse toxicity assay. However, it has been shown that their results are often biased because of the matrix effects. To eliminate the possible interferences in the algal matrices, a new solid-phase extraction (SPE) method using silica gel as a sorbent was developed and evaluated. Results show that this SPE method could not only reduce the toxicity of the Microcystis samples towards brine shrimp by $50-80 \%$ but also eliminate 90-100\% of the endogenous phosphatase activity from Spirulina and Chlorella samples, thus improving the determination of microcystins in algal samples using either of the two bioanalytical methods. The application of this SPE method as an off-line cleanup for high-performance liquid chromatography (HPLC) with UV detection is also described in this study. After SPE, the HPLC chromatograms of Microcystis samples have clear baselines that have no interferences with the analyte peaks.
\end{abstract}

(C) 2006 Elsevier B.V. All rights reserved.

Keywords: Solid-phase extraction (SPE); Microcystis; Microcystin (MC); Artemia assay; Protein phosphatase assay; HPLC; Mouse Bioassay; Algal dietary supplement; Cyanobacteria

\section{Introduction}

Toxic cyanobacteria has become a serious health problem in the past decades. Some toxic species tend to proliferate massively in eutrophic waters and thus become potentially hazardous [1-3]. The most frequently reported cyanotoxins are hepatotoxins, mainly the cyclic heptapeptides known as microcystins (MCs) (Fig. 1). MCs are extremely potent toxins; a few micrograms of MCs kill laboratory mice readily because of acute liver failure and hemorrhage [4], and under chronic exposure they exert strong tumor-promoting activity [5]. The mechanisms of MC-induced liver toxicity are generally regarded to be mediated

\footnotetext{
* Corresponding authors. Tel.: +8862 3366 2879; fax: +8862 23629919

E-mail addresses: cohens.tw@yahoo.com.tw (Y.-M. Chen), unijohn@ntu.edu.tw (H.-N. Chou).
}

via the inhibition of protein phosphatases 1 (PP-1) and 2A (PP$2 \mathrm{~A}$ ), the two major serine/threonine phosphatases in eukaryotic cells [6-8].

The acute toxicity and tumor promoting property of MCs as well as their widespread occurrence raise concern for their possible contamination of drinking water as well as algal dietary supplements. High-performance liquid chromatography (HPLC) with UV, photodiode array (PDA), and mass spectrometry (MS) detection are widely used methods for the identification and quantitation of MCs once some of the MC standards are made available [9-13]. However, there are still no available certified standards for MCs. In addition, purification and concentration of samples are usually required for $\mathrm{LC}$ with $\mathrm{UV}$ detection because of the lower specificity and sensitivity to MCs. A number of toxicity assays have been designed and evaluated for screening purposes. The mouse bioassay has long been recognized as the standard method for cyanotoxins including MCs [13]. Owing to 


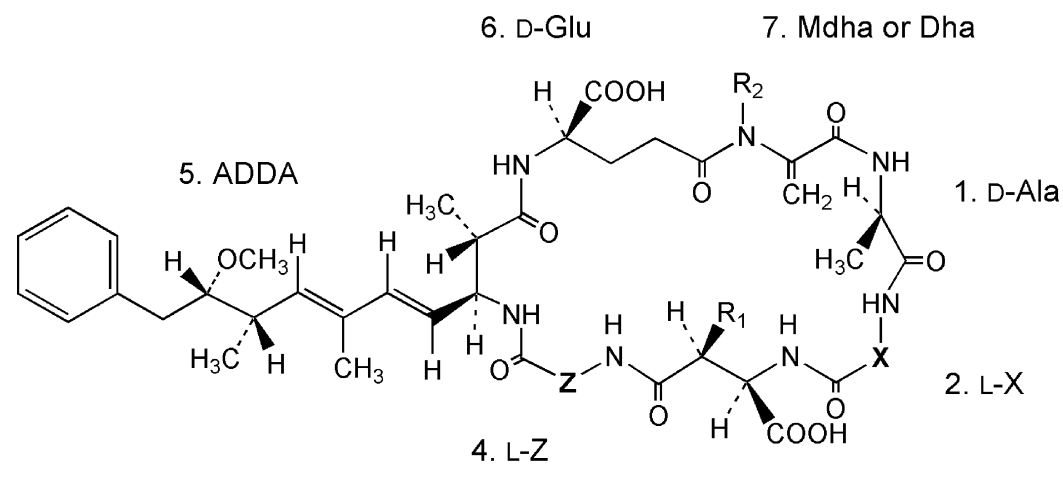

3. D-MeAsp or D-Asp

Fig. 1. General structure of MCs. MeAsp, Mdha, ADDA are abbreviations of methylaspartic acid, methyldehydroalanine, and 3-amino-9-methoxy-2,6,8-trimethyl10-phenyldeca-4,6-dienoic acid, respectively.

ethical problems and also an increasing opposition to the use of higher animals for toxicity tests, other types of bioassays have been evaluated and used. The most popular one has been the brine shrimp assay using the larvae of Artemia salina [14-17]. Although the brine shrimp assay has been widely used, it is not always clear whether Artemia larvae are reacting to MCs or to other compounds co-extracted in the sample matrices [14,17]. A biochemical method using isolated protein phosphatase has been designed and used for the analysis of MCs [18-21]. This in vitro method is much more sensitive than the traditional bioassays, and as the measurement is based on the targeted enzymes, the toxicity of samples of higher animals can be predicted. However, the endogenous phosphatase activity observed in sample matrices always masks the presence of MCs in samples and leads to an underestimation of the toxin contents $[19,21]$. Owing to the difficulties described above with these analytical and bioanalytical methods, it is clear that the removal of matrix interferences and also the concentration of MCs are the only ways to improve the measurement of MCs.

In this study, a simple solid-phase extraction (SPE) method was designed and evaluated for its efficiency to remove matrix interferences that could influence the results of phosphatase assays, Artemia assays, and HPLC with UV detection, as well as its performance on the recoveries of different MCs. In addition, different HPLC columns and mobile phases were compared for their efficiencies on separation of various MCs, which can greatly influence the identification of MCs by using HPLC with UV detection.

\section{Material and methods}

\subsection{Caution}

MCs are hazardous because of their potent hepatotoxicity and tumor-promoting activity and should be handled carefully.

\subsection{Materials}

\subsubsection{Chemicals}

For the reagents used in liquid chromatography, methanol was purchased from J.T. Baker (Phillipsburg, NJ, USA), ammo- nium acetate was purchased from Sigma-Aldrich (St. Louis, MO, USA) and deionized water was produced by passing distilled water through a Milli-Q System (Millipore, Bedford, MA, USA). Pure MCs (i.e. MC-LR, -RR, -FR, -WR, -YR, -RA, $\left[{ }^{7}\right.$ Dha $]$ MC-LR, $\left[{ }^{3} \mathrm{D}\right.$-Asp]MC-FR, and -WR) were purified from a Microcystis strain M.TN-2 and a wild bloom sample collected in a previous study [22]. The $p$-nitrophenyl phosphate ( $p$ NPP), dithiothreitol (DTT), EDTA, Tris- $\mathrm{HCl}, \mathrm{MnCl}_{2}, \mathrm{NaOH}$, and bovine serum albumin used in the phosphatase assay were purchased from Sigma-Aldrich.

Two types of sorbents, silica gel and ODS gel were used in the solid-phase extraction procedure. The former was purchased from J.T. Baker (Baker silica gel $40 \mu \mathrm{m}$ flash chromatography packing, Phillipsburg, NJ, USA), and the latter, Cosmosil 40 C18-RPEP gel donated by Nacalai Tesque (Kotyo, Japan). Both have the same particle size of $40 \mu \mathrm{m}$.

\subsubsection{Enzyme and animals}

Catalytic subunits of protein phosphatase 1 (PP-1c) were purchased from Calbiochem (\#539493, San Diego, Ca, USA) and were provided in aliquots of $7 \mu \mathrm{g}$ of protein with $100 \mathrm{U}$ of activity; a unit being equivalent to $1 \mathrm{nmol} p \mathrm{NPP}$ hydrolyzed per minute. For animal toxicity assays, the mice were male (ICR strain) weighing $20 \pm 1 \mathrm{~g}$, kindly donated by the Animal Supply of National Taiwan University Hospital (Taipei, Taiwan). The brine shrimp used were larvae of Artemia hatched from dry eggs of Ocean Star Corp (Snowville, UT, USA) 1 day before assay.

\subsubsection{Preparation of algal samples and toxin standard solution}

Two types of samples were collected and subjected to the assays. Toxic cyanobacteria samples were 6 strains of $M$. aeruginosa isolated from Taiwan with diverse toxicities to mice or brine shrimp [16]. According to [16], these strains were cultured in modified Fitzgerald Media at $25 \pm 1{ }^{\circ} \mathrm{C}$, illuminated at $25 \mu$ Einm $^{-2} \mathrm{~s}^{-1}$ with a fluorescent light for $12 \mathrm{~h}$ per day. During late exponential phase, the cells were collected by continuous centrifugation. Algal dietary supplement samples were eight Chlorella or Spirulina products purchased from local drug stores, and concentration of MCs in these samples was 
determined to be lower than $40 \mathrm{ppb}$ [19]. An MC-LR solution was prepared by dissolving $20 \mathrm{mg}$ of pure MC-LR in $\mathrm{MeOH}$ at a concentration of $1 \mathrm{mg} / \mathrm{mL}$ to serve as an in-house standard for toxicity assays and HPLC analysis. The other MCs were prepared as solutions with approximately $0.1 \mathrm{mg} / \mathrm{mL}$ in $\mathrm{MeOH}$ to serve as standards for the identification of MCs by HPLC.

\subsection{Experimental procedures}

\subsubsection{Extraction}

For algal dietary supplements, three tablets from one package were randomly selected and ground. Hundred milligram aliquots of the algal powder were extracted with $2 \times 10 \mathrm{~mL} \mathrm{MeOH}$ or $5 \%$ acetic acid aqueous solution. Both extracts were submitted to the phosphatase assay. The same $\mathrm{MeOH}$ or $5 \%$ acetic acid extracts were prepared again and then treated with SPE using silica gel or ODS gel, respectively. These procedures were designed to understand the possible matrix effects when different extraction solvents were used and also to check if the matrix effects can be removed by SPE using different sorbents. Other methanolic extracts from Chlorella and Spirulina products (sample code Vd-C and Vd-S) were prepared and spiked with MC-LR to give a concentration of $5 \mathrm{ng} / \mathrm{mL}$; half of the extract was directly submitted to the phosphatase assay, and the other half of the solution was treated by silica gel prior to the assay. In this manner, the efficiency of silica gel to remove matrix interferences and also the recoveries of MC-LR were evaluated.

Using the same spike method, the recoveries of MC-LR, MCRR from silica gel were evaluated according to the analysis of HPLC. Another $100 \mathrm{mg}$ aliquots of Vd-C were extracted with $2 \times 10 \mathrm{~mL} \mathrm{MeOH}$, then spiked with MC-LR and MC-RR to give final concentration of $5 \mathrm{ng} / \mathrm{mL}$ each. Half of the solutions were treated by silica gel according to Section 2.3.3, and then the toxin fractions were analyzed by HPLC, according to the methods described in Section 2.3.6.

The crude extracts of toxic Microcystis strains were prepared by extracting $200 \mathrm{mg}$ of Microcystis lyophilized cells with $3 \times 40 \mathrm{~mL} \mathrm{MeOH}$. The extracts were then submitted for animal toxicity assays or high performance liquid chromatography coupled to a UV detector (HPLC-UVD).

\subsubsection{Solid-phase extraction}

0.1 gram silica or ODS gel was packed into a plastic column with $0.6 \mathrm{~cm}$ i.d. For the SPE using silica gel, methanolic extracts of the samples were dried, redissolved in $0.5 \mathrm{~mL}$ ethyl acetate/isopropanol (4:3, v/v), and then loaded onto a column preconditioned with $2 \mathrm{~mL}$ ethyl acetate/isopropanol (4:3, v/v). After loading, the column was washed with $2 \mathrm{~mL}$ of the preconditioning solution and then eluted using $0.5 \mathrm{~mL} \mathrm{MeOH}$. The ODS SPE was operated according to Kaya et al. [10]. The extract was obtained using a 5\% acetic acid aqueous solution and then loaded directly onto an ODS column that was pre-washed with $0.5 \mathrm{~mL} \mathrm{MeOH}$ followed by the $5 \%$ acetic acid aqueous solution. After loading, the column was washed with $1 \mathrm{~mL} 20 \%$ aqueous $\mathrm{MeOH}$ and then eluted using $0.5 \mathrm{~mL} \mathrm{MeOH}$.

\subsubsection{Phosphatase assay}

The crude extracts of algal supplements and also the extracts after cleanup were evaporated and redissolved in $1.25 \mathrm{~mL}$ $\mathrm{MeOH}$. From this, a $30 \mu \mathrm{L}$ aliquot was taken for the phosphatase assay performed according to the standard protocol of phosphatase assay designed by Calbiochem. Briefly, a solution containing $50 \mathrm{mM}$ Tris- $\mathrm{HCl}, 0.1 \mathrm{mM}$ EDTA, $5 \mathrm{mM}$ dithiothreitol, and $0.2 \mathrm{mM} \mathrm{MnCl}_{2}, 0.2 \mathrm{mg} \mathrm{mL}^{-1}$ bovine serum albumin, carefully adjusted to $\mathrm{pH} 7.0$ using $0.1 \mathrm{~N} \mathrm{NaOH}$, was prepared as the buffer solution. Using this solution, three other solutions were prepared. The PP- $1 \mathrm{c}$ was diluted to $1 \mathrm{U} \mathrm{mL}^{-1}$ as the enzyme solution, $p$-NPP of $250 \mathrm{mM}$ was prepared as substrate solution, and the $30 \mu \mathrm{L}$ sample was diluted with $970 \mu \mathrm{L}$ buffer. The assay was carried out in a 96-well transparent microplate, and the optimized procedure for the best sensitivity was as follows: $100 \mu \mathrm{L}$ of buffer solution was mixed with $50 \mu \mathrm{L}$ of sample and enzyme solutions, pre-incubated for $10 \mathrm{~min}$, and then the reaction was started by adding $50 \mu \mathrm{L}$ substrate solution. The plate was kept at $30^{\circ} \mathrm{C}$ for $1 \mathrm{~h}$ and then the change of absorbance at $405 \mathrm{~nm}$ due to the decomposition of $p$-NPP substrate was measured. To account for the non-enzymatic degradation of the substrate, a blank group without sample or enzyme added was prepared for each plate. The inhibition activity of each sample was calculated by the change of absorbance and expressed as a percentage activity of the control, in which $30 \mu \mathrm{L} \mathrm{MeOH}$ was added in the sample solution instead of toxin or algal extracts.

The toxin content of each sample was calculated according to the standard curve of MC-LR and presented as the unit of MC-LR equivalent. To create a standard curve, MC-LR with final concentrations of $20,40,80,160,320$, and $640 \mathrm{pg} / \mathrm{mL}$ was prepared and analyzed in triplicate. The relationship between the percentage activity of control and toxin concentration was fit by a $\log$ equation using the nonlinear regression function in Microsoft Excel.

\subsubsection{Mouse toxicity assay}

From the methanolic extract of each Microcystis strain, 14.4, $7.2,3.6,1.8,0.9,0.45$, and $0.23 \mathrm{~mL}$ were aliquoted, evaporated, re-suspended in $3 \mathrm{~mL}$ saline solution $(0.95 \%)$, and then injected intraperitoneally to three mice. This gave seven doses equivalent to $400,200,100,50,25,12.5$, and $6.3 \mathrm{mg}$ dry cells per kilogram of mouse. Four hours later, the mortality was recorded [16] and their toxicities were calculated by probit analysis represented by $\mathrm{LD}_{50}, 50 \%$ lethal dose [23]. Using this same method, a MCLR standard solution was aliquoted, dried, redissolved in saline solution, and then injected into mice. Six doses equivalent to $200,100,50,37.5,25$, and $12.5 \mu \mathrm{g}$ per kilogram mice were prepared with six replicates for each dose.

\subsubsection{Artemia toxicity assay}

Following the method established in our previous study [16], larvae of Artemia salina hatched from dried eggs were suspended in seawater at approximately 250 individuals per milliliter. Fifty microliter was aliquoted into each well in a 96well microplate. Methanolic extracts of Microcystis strains or toxin fractions obtained from silica gel SPE were analyzed. For the first, $48 \mathrm{~mL}$ of the solution was dried, re-suspended 
in $0.5 \mathrm{~mL}$ seawater to give a concentration of $160 \mathrm{mg} / \mathrm{mL}$ in terms of lyophilized cell mass, and then diluted to another five concentrations by $1 / 2$ serial dilution using seawater. For each concentration, $50 \mu \mathrm{L}$ sample solution was added to a well and gently mixed with larvae, $n=4$. After $24 \mathrm{~h}$, mortalities were recorded. $\mathrm{LC}_{50}$, the concentration causing $50 \%$ deaths in the larvae for each strain, was calculated by probit analysis. For the latter, another $48 \mathrm{~mL}$ of the methanolic extracts were evaporated, redissolved in ethyl acetate/isopropanol solution, and treated by silica gel SPE. The toxin fraction was collected, dried under an $\mathrm{N}_{2}$ stream, re-dissolved in $0.5 \mathrm{~mL}$ seawater, diluted using the same $1 / 2$ series, and then tested for toxicity. In this manner, MC-LR standard solution was aliquoted, dried, redissolved in seawater as final concentrations of $20,10,5,2$, and $1 \mu \mathrm{g} / \mathrm{mL}$, and then submitted to the assay.

\subsubsection{High-performance liquid chromatography}

The liquid chromatography component consisted of a Hitachi (Tokyo, Japan) L-6200 pump and a L-4200 UV-vis detector operated at $238 \mathrm{~nm}$. Two different analytical columns i.e. Cosmosil 5C18-MS (Nacalai tesque, Kyoto, Japan) and Luna phenyl-hexyl (Phenomenex, Torrance, CA, USA), both with the dimensions of $4.6 \mathrm{~mm} \times 250 \mathrm{~mm}$ and particle size of $5 \mu \mathrm{m}$, were compared for their efficiencies on the separation of MCs. The mobile phase used for both was $0.01 \mathrm{M}$ ammonium acetate/acetonitrile or water/acetonitrile containing $0.01 \%$ TFA with a flow rate of $1 \mathrm{~mL} / \mathrm{min}$ at $25^{\circ} \mathrm{C}$.

The optimal LC system was used for the analysis of MCs in Microcystis samples and also for checking the recoveries of spiked MC-LR and MC-RR as described in Section 2.3.1. For the former, $10 \mathrm{~mL}$ of the methanolic extracts of Microcystis were dried under an $\mathrm{N}_{2}$ stream, re-dissolved in $0.5 \mathrm{~mL}$ ethyl acetate/isopropanol (4:3, v/v), and then treated by silica gel SPE according to Section 2.3.2. Five microliter of the toxic fraction was injected. For the latter, toxin fraction obtained from SPE was evaporated, redissolved in $50 \mu \mathrm{L}$ of $20 \%$ aqueous $\mathrm{MeOH}$, then $5 \mu \mathrm{L}$ was injected, $n=3$. To create standard curves, MCLR or MC-RR with final concentrations of $0.2,0.4,0.8,1.6$, and $3.2 \mu \mathrm{g} / \mathrm{mL}$ in pure $\mathrm{MeOH}$ were prepared, and for each concentration, $5 \mu \mathrm{L}$ was injected, $n=3$. The relationship between peak area and toxin concentration was fit by a linear equation using the linear regression function in Microsoft Excel.

\subsubsection{MALDI-TOF MS}

One microliter of the toxin fraction from SPE was mixed with $4 \mu \mathrm{L}$ of $\alpha$-cyano-hydroxy-cinnamic acid ( $\alpha$-CHCA), a commercialized matrix purchased from Agilent (Palo Alto, CA, USA). Half a microliter of the mixture was first added onto a probe, and then analyzed by an Agilent G2025A MALDI-TOF MS operated in positive mode. As soon as the pressure in flight tube was lower than $10^{-6}$ Torr, the sample was desorbed by using a nitrogen laser $(\lambda=337 \mathrm{~nm})$ that was set at $0.95 \mu \mathrm{J}$. Results from 40 shots were accumulated to get a better spectrum with higher $\mathrm{S} / \mathrm{N}$ ratio and better reproducibility. MCs were mainly identified according to the $\mathrm{m} / \mathrm{z}$ values of their protonated molecular ions.

\section{Results}

\subsection{Analysis of the algal dietary supplement samples using phosphatase assay}

Strong matrix effects were observed when the crude extracts were analyzed. A 40-60\% higher phosphatase activity than that of the control group was observed when methanolic extracts were analyzed. In contrast, a 30-60\% lower phosphatase activity was observed for the samples extracted by $5 \%$ acetic acid. The ODS column was less efficient than the silica gel column in removing the matrix interferences. An 18-38\% decrease of phosphatase activity was still found after the treatment of the acetic acid solutions by ODS column. In contrast, the matrix effects contained in methanolic extracts were almost completely removed by silica gel SPE (Table 1). According to the results, $90-100 \%$ endogenous phosphatase activity has been eliminated from different samples by using the silica gel SPE cartridge.

The efficiency of the removal of the matrix interferences from methanolic extracts as well the recovery rate for MC-LR of the silica gel SPE were further evaluated with spikes. Using the MC-LR calibration curve $(X=$ concentration of MC-LR, $\mathrm{ng} / \mathrm{mL}$, $Y=\%$ activity of the control; $\left.Y=-0.28 \operatorname{Ln} X+0.39, R^{2}=0.9634\right)$ with a working range from 0.02 to $0.64 \mathrm{ng} / \mathrm{mL}$, the toxin contents of the spiked samples before and after SPE treatment were determined as shown in Table 2. This revealed that the silica gel SPE can not only eliminate the endogenous phosphatase activity

Table 1

Results of PP-1 inhibition assay of algal samples treated by different SPE methods

\begin{tabular}{|c|c|c|c|c|c|}
\hline \multirow[t]{3}{*}{ Products } & \multirow[t]{3}{*}{ Code } & \multicolumn{4}{|l|}{ SPE methods } \\
\hline & & \multicolumn{2}{|l|}{ ODS } & \multicolumn{2}{|l|}{ Silica gel } \\
\hline & & $\%$ activity of control & MCYST-LR equivalent (ppb) & $\%$ activity of control & MCYST-LR equivalent (ppb) \\
\hline \multirow[t]{4}{*}{ Chlorella } & VD-C & $68 \pm 5$ & $82 \pm 6$ & $97 \pm 3$ & $<25$ \\
\hline & TC-C & $67 \pm 2$ & $86 \pm 2$ & $99 \pm 3$ & $<25$ \\
\hline & FE-C & $68 \pm 1$ & $78 \pm 1$ & $99 \pm 3$ & $<25$ \\
\hline & GB-C & $71 \pm 2$ & $65 \pm 2$ & $98 \pm 7$ & $<25$ \\
\hline \multirow[t]{4}{*}{ Spirulina } & VD-S & $82 \pm 7$ & $<25$ & $103 \pm 3$ & $<25$ \\
\hline & TC-S & $68 \pm 5$ & $080 \pm 6$ & $099 \pm 6$ & $<25$ \\
\hline & AK-S & $66 \pm 2$ & $91 \pm 3$ & $102 \pm 6$ & $<25$ \\
\hline & NP-S & $63 \pm 4$ & $111 \pm 6$ & $104 \pm 11$ & $<25$ \\
\hline
\end{tabular}


Table 2

Results of PP-1 analysis for the spiked samples before and after silica gel SPE

\begin{tabular}{lll}
\hline Samples & \multicolumn{2}{l}{ Analytical result relative to the spiked value $(\%)$} \\
\cline { 2 - 3 } & Crude extract & Toxin fraction of SPE \\
\hline VD-C & $89.2 \pm 8.2$ & $101.9 \pm 9.4$ \\
VD-S & $92.4 \pm 3.6$ & $102.2 \pm 5.6$ \\
\hline
\end{tabular}

that masks the MC content in the crude extracts but also has a good recovery rate for the spiked MC-LR. The good recovery of MC-LR was further confirmed by HPLC as $97 \pm 4 \%$. In contrast, a lower recovery of MC-RR was obtained. According to the result of HPLC, recovery of MC-RR from the silica gel SPE cartridge was $82 \pm 5 \%$.

\subsection{Analysis of microcystis samples by animal assays}

The success in removing matrix interferences by silica gel prompted us to try the same method to remove the possible matrix effects from toxic cyanobacteria for the brine shrimp assay. The toxicities of MC-LR and methanolic extracts of Microcystis with or without SPE treatment were assayed using mice and brine shrimp assays, respectively, and the results are all shown in Table 3. Obviously, the silica SPE greatly reduced the toxicities of extracts toward brine shrimp. To investigate whether the reduction of toxicity to brine shrimp after SPE is helpful to improve the determination of MCs by brine shrimp assay, all of the toxicity results represented as $\mathrm{LD}_{50}$ or $\mathrm{LC}_{50}$ were converted to the same MC-LR equivalent unit by using the following equation:

$$
\begin{aligned}
& \text { LR equivalent }\left(\frac{m g \text { MC-LR }}{\mathrm{g} / \text { sample }}\right) \\
& =\left(\frac{\mathrm{LD} 50, \mathrm{LC} 50 \text { or IC50 of MC-LR }}{\mathrm{LD} 50, \mathrm{LC} 50 \text { or IC50 of sample }}\right) \times 1000
\end{aligned}
$$

According to the MC-LR equivalents obtained from different assays (Table 4), the toxicities of the samples toward brine shrimp and mice were compared by linear regressions. As the regression results show in Fig. 2a, crude extracts exerted stronger toxicities in the brine shrimp assay than on the mouse,

Table 3

Toxicities of MC-LR and Microcystis strains

\begin{tabular}{lllr}
\hline Sample & $\begin{array}{l}\text { Mouse assay, } \mathrm{LD}_{50} \\
(\mathrm{mg} / \mathrm{kg} \text { mouse })\end{array}$ & \multicolumn{2}{l}{ Artemia assay, $\mathrm{LC}_{50}(\mathrm{mg} / \mathrm{mL})$} \\
\cline { 3 - 4 } & & No SPE & With SPE \\
\hline $\begin{array}{l}\text { Pure MC } \\
\text { MC-LR }\end{array}$ & $0.05 \pm 0.01$ & $0.006 \pm 0.001$ & \\
\multicolumn{2}{l}{ Microcystis strain } & & \\
M.TY-1 & $010 \pm 1$ & $1.0 \pm 0.2$ & $1.1 \pm 0.2$ \\
M.TY-2 & $071 \pm 5$ & $2.4 \pm 0.6$ & $4.9 \pm 1.0$ \\
M.CY-1 & $097 \pm 12$ & $4.6 \pm 0.7$ & $10.9 \pm 1.2$ \\
M.TN-2 & $102 \pm 14$ & $3.2 \pm 0.5$ & $7.8 \pm 0.6$ \\
M.TN-3 & $051 \pm 7$ & $1.3 \pm 0.3$ & $6.3 \pm 0.7$ \\
M.TN-4 & $035 \pm 3$ & $0.6 \pm 0.2$ & $3.3 \pm 0.3$ \\
\hline
\end{tabular}

Table 4

Toxin content of Microcystis strains presented by MC-LR equivalent (mg/g dry algae)

\begin{tabular}{lccc}
\hline Microcystis strain & Mouse assay & \multicolumn{2}{c}{ Artemia assay } \\
\cline { 3 - 4 } & & No SPE & With SPE \\
\hline M.TY-1 & $5.0 \pm 0.5$ & $6.0 \pm 1.2$ & $5.5 \pm 1.0$ \\
M.TY-2 & $0.7 \pm 0.1$ & $2.5 \pm 0.6$ & $1.2 \pm 0.2$ \\
M.CY-1 & $0.5 \pm 0.1$ & $1.3 \pm 0.2$ & $0.6 \pm 0.1$ \\
M.TN-2 & $0.5 \pm 0.1$ & $1.9 \pm 0.3$ & $0.8 \pm 0.1$ \\
M.TN-3 & $1.0 \pm 0.1$ & $4.6 \pm 1.1$ & $1.0 \pm 0.2$ \\
M.TN-4 & $1.4 \pm 0.1$ & $10.0 \pm 3.3$ & $1.8 \pm 0.2$ \\
\hline
\end{tabular}

this means, some materials that are selectively toxic to brine shrimp existed in most crude extracts, especially the extracts from M.TN-3 and M.TN-4. By using the silica gel SPE, these interferences can be removed, and the brine shrimp can react much more specifically to MCs (Fig. 2b).
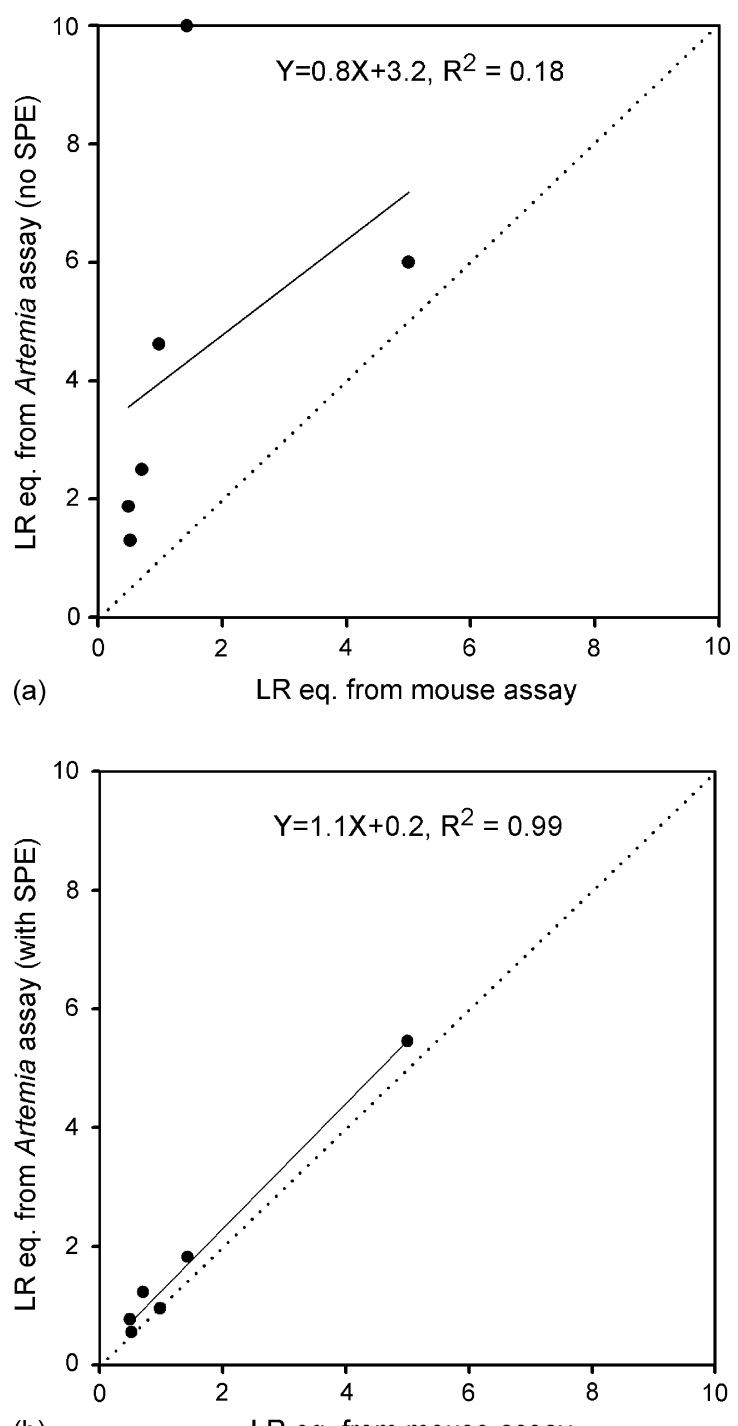

(b)

LR eq. from mouse assay

Fig. 2. Relationships between mouse toxicity assay and (a) Artemia toxicity assay with no solid-phase extraction before assay, (b) Artemia toxicity assay with solid-phase extraction before assay. 


\subsection{HPLC and MALDI-TOF MS}

As the results shown in Fig. 3a, when the Cosmosil column was used, the mobile phase with $0.01 \%$ TFA did not separate well for the MCs and demethyl MCs. It was somewhat improved by using the ammonium acetate mobile phase as mobile phase (Fig. 3b). In contrast, the Phenomenex column gave a better separation of MCs and shorter analytical time than the Cosmosil

(a)

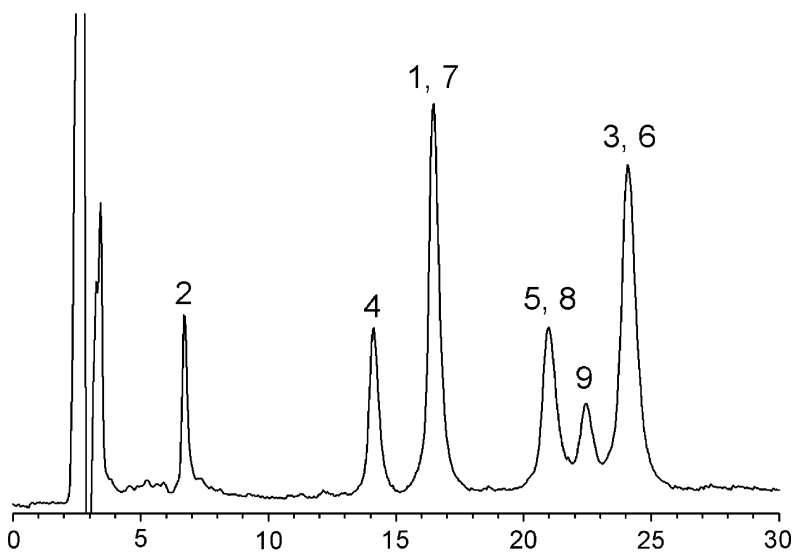

(b)

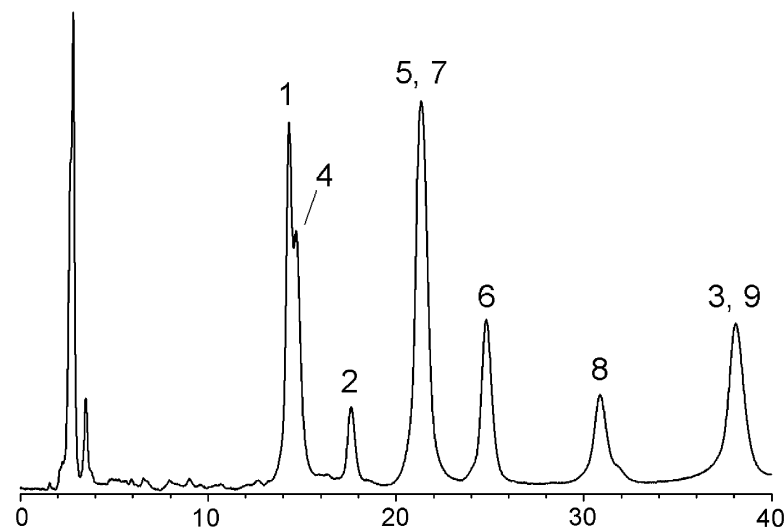

(c)

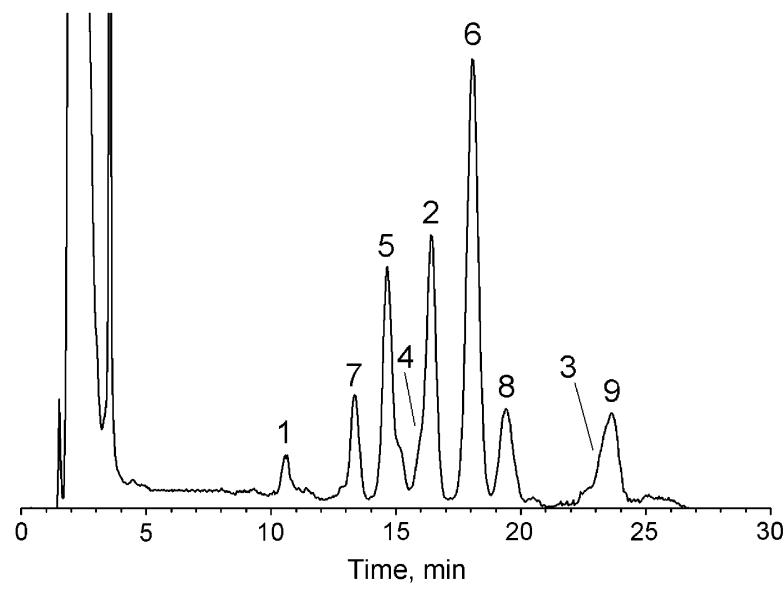

Fig. 3. Separation of MC-LR (1), -RR (2), -RA (3), -YR (4), -FR (5), WR (6), [Dha $\left.{ }^{7}\right] M C-L R(7),\left[D-A s p^{3}\right]$ MC-FR (8), and -WR (9) with different HPLC columns or mobile phases. (a) Cosmosil column with water/acetonitrile, $0.05 \%$ TFA as mobile phase, (b) Cosmosil column with $0.01 \mathrm{M}$ ammonium acetate/acetonitrile as mobile phase, (c) Phenomenex column with $0.01 \mathrm{M}$ ammonium acetate/acetonitrile as mobile phase.
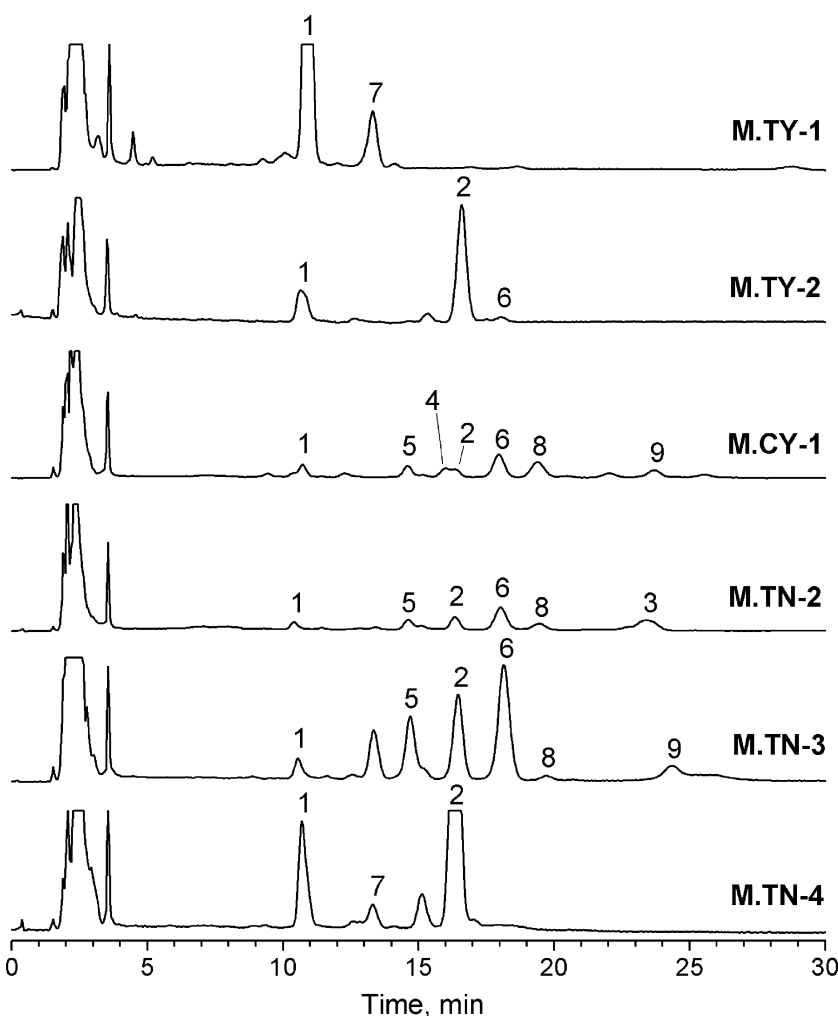

Fig. 4. HPLC chromatograms of Microcystis strains which contains MCs i.e. MC-LR (1), -RR (2), -RA (3), -YR (4), -FR (5), -WR (6), [Dha ${ }^{7}$ MC-LR (7), [D-Asp ${ }^{3}$ ]-FR (8), and -WR (9)

column when the same ammonium acetate mobile phase was used, as shown in Fig. 3c.

The silica gel SPE can remove not only the hydrophobic materials that may irreversibly adsorb on the gel of HPLC column but also the interferences that influence the detection of MCs by HPLC-UVD. As the chromatograms show in Fig. 4, the baselines are clear and almost no other peaks other than MCs are observed. The presence of these MCs was further confirmed by MALDI-TOF MS (Fig. 5).

\section{Discussion}

The co-extraction of matrix interferences has hindered the reliability of the use of Artemia and protein phosphatase assays for the analysis of MCs in algal samples. Our silica gel SPE method has been proven to be useful to remove the interferences for the Artemia assay and the phosphatase assay from different algal samples as shown in our results.

In comparison with ODS gel, which is the most universal sorbent for the sample preparation before analysis of MCs $[10,21,24,25]$, the silica gel appeared to be more powerful in eliminating the materials that influence the phosphatase activity. Also, an immunosorbent has been proven to be more powerful than ODS to eliminate the matrix effects from water and algal samples [20]. This method has an excellent concentration factor of 10 , which is higher than silica gel factor of 5 . However, the performance of the silica gel sorbent seems no worse than the immunoextraction for the removal of matrix effects from 

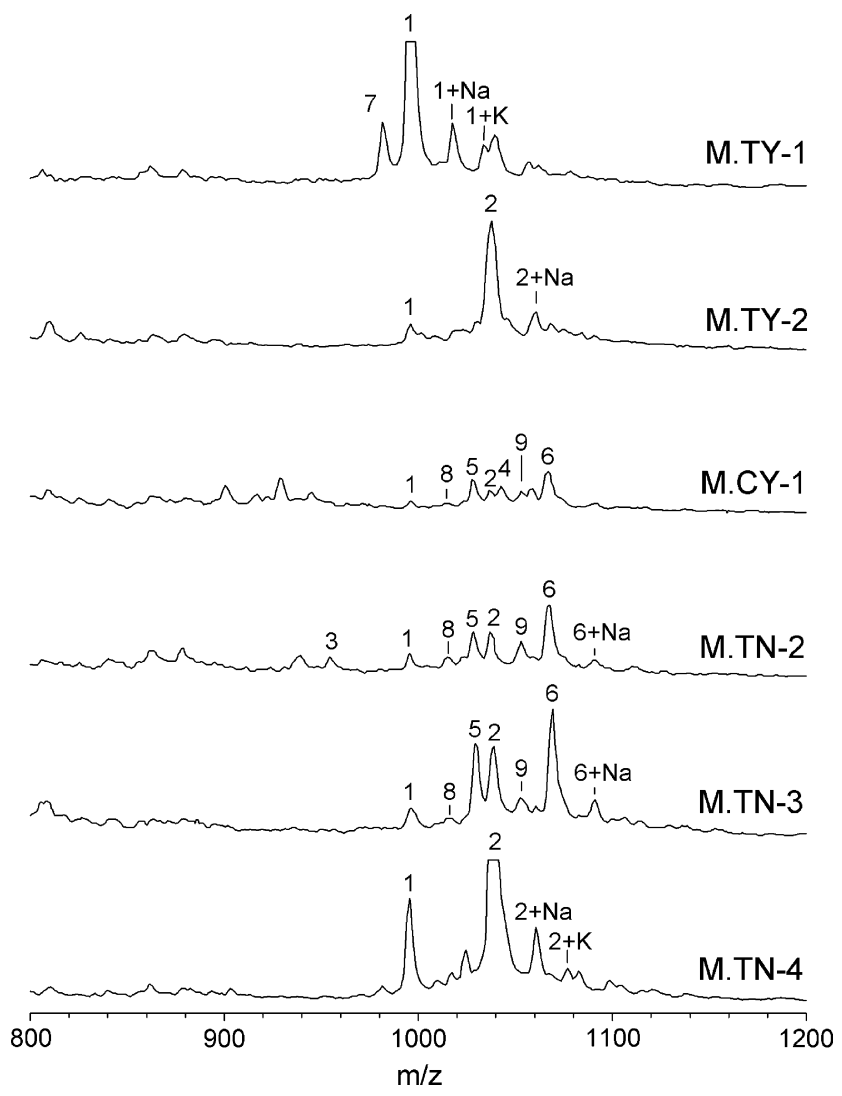

Fig. 5. MALDI-TOF MS spectrums of Microcystis strains. 1-9 are $[\mathrm{M}+\mathrm{H}]^{+}$ signals of MC-LR, -RR, -RA, -YR, -FR, -WR, [Dha $\left.{ }^{7}\right] M C-L R$, [D-Asp $\left.{ }^{3}\right] M C-$ FR, and -WR. " $1+\mathrm{Na}$ " \& " $1+\mathrm{K}$ " are $[\mathrm{M}+\mathrm{Na}]^{+} \&[\mathrm{M}+\mathrm{K}]^{+}$signals of MC-LR, and " $2+\mathrm{Na}$ " \& " $2+\mathrm{K}$ " are $[2+\mathrm{Na}]^{+}$and $[2+\mathrm{K}]^{+}$signals of MC-RR.

algal samples. In addition, the immunosorbent is not commercially available and difficult to dispose. By coupling the silica gel SPE to our optimized phosphatase assay, a MC concentration of $1 \mathrm{ppm}$ can be accurately determined, and theoretically the limit of detection can reach $25 \mathrm{ppb}$, which is much lower than the regulatory limit of $1 \mathrm{ppm}$ established for algal dietary supplements [3], and by coupling the silica gel method to the brine shrimp assay, the brine shrimp can react specifically to MCs. By loading similar amount of MCs (30-55 ng) in our study as in Rapala et al.'s work [21], we obtained better MC-LR recovery $(97 \%$ versus $\sim 90 \%$ in both $\mathrm{C} 18$ and Oasis columns) and intermediate MC-RR recovery ( $82 \%$ versus $\sim 99 \%$ for Oasis and $\sim 8 \%$ for $\mathrm{C} 18$ column, respectively). Obviously, the recovery rates for C18 columns vary greatly among different MCs. In contrast, both Oasis and our silica gel columns are more consistent for different MCs recoveries and their recovery rates are comparable. However, as the cost of silica sorbent is much cheaper than Oasis, our silica gel SPE is the preferred method for MCs extraction. This is especially important for routine analyses by using Artemia assays, phosphatase assays, or HPLC that can consume large amounts of sorbent. Also, the silica gel method is much easier for use. The MCs from methanolic extracts will adsorb and then co-elute with a dark-green pigment, which can serve as a marker for toxin collection and also prevent the breakthrough of MCs due to overloading. In addition to its usefulness with bioanalytical methods, the silica gel method has also been proven to be useful to serve as an off-line solid-phase extraction cleanup method for HPLC analysis to remove interferences and also to preconcentrate the toxins. It is especially important when the HPLC-UVD is used for the analysis of trace MCs in complex matrixes [19].

The phosphatase assay is good for the screening of MC related compounds, as it is fast, sensitive, and reliable [18-21]. We have used the same phosphatase assay for the screening of toxic Microcystis, in which less than $0.2 \mathrm{mg}$ sample was submitted for the assay. In this manner, inhibition activity of the samples was well correlated to the sample toxicity in mice (data not shown). Here, the crude methanolic extracts can be analyzed directly with little matrix effect. In contrast, the analysis of MCs in the algal dietary supplements was a challenge, as the toxin content was much lower than in the toxic cyanobacteria. To get a limit of detection (LOD) as low as $25 \mathrm{ppb}, 2.5 \mathrm{mg}$ instead of $0.2 \mathrm{mg}$ sample would need to be analyzed, which results in a serious matrix effect.

The major problem of the brine shrimp assay for screening of MCs in algal samples is the false positives caused by the materials that are low in toxicity to mice but highly toxic to brine shrimp [14]. It has been reported that long-chain unsaturated fatty acids could inhibit $\mathrm{Na}^{+} / \mathrm{K}^{+}$-ATPase in Artemia [26], and also the long chain fatty acids produced by $M$. aeruginosa could kill fish because of inhibitory activities for $\mathrm{Na}^{+} / \mathrm{K}^{+}$-ATPase located on the fish gill [27]. We speculate that similar components produced by Microcystis can kill brine shrimp larvae in the same manner when they are immersed with brine shrimps, and most importantly, those compounds can be easily removed by our SPE method. The other factor that can greatly influence the results of Artemia assays is the storage time of eggs. An $\mathrm{LC}_{50}$ value of $22.3 \mu \mathrm{g} / \mathrm{ml}$ of MC-LR was obtained in our previous study [16], which is much higher than the value of $5.7 \mu \mathrm{g} / \mathrm{ml}$ obtained in the present study using the same batch of eggs. To prevent the alteration of aged Artemia on $\mathrm{LC}_{50}$ and to make the $\mathrm{LC}_{50} \mathrm{com}$ parable, it is helpful to convert the $\mathrm{LC}_{50}$ of the samples to the MC-LR equivalent unit based on the $\mathrm{LC}_{50}$ of MC-LR analyzed at the same time. It is a rather simple way to present the toxicity of Microcystis extracts.

$\mathrm{MeOH}$, water, and mixture of the two are common solvents for MC extraction from algal samples and have been evaluated for the extraction of a number of MCs from different samples (reviewed by Lawton and Edwards [28]). However, it is still controversial as to which is the most appropriate solvent. In the study of Gjølme et al. [29], pure water, pure $\mathrm{MeOH}$, and 70\% aqueous $\mathrm{MeOH}$ performed equally well for the extraction of MC-RR from a cultured Microcystis strain. Fastner et al. [30] found the extraction efficiency of $\mathrm{MeOH}$, water, and $75 \%$ aqueous $\mathrm{MeOH}$ varied among samples. In some samples the three media performed equally, but in others, especially field samples, pure $\mathrm{MeOH}$ gave only $50 \%$ recovery of total MCs compared with others. Further investigation revealed that the lower recovery was mainly due to the low recovery of MC-RR. Lower performances of pure $\mathrm{MeOH}$ and water were observed in the study of Ward et al. [31], which compared the performance of aqueous solutions with different percentages of $\mathrm{MeOH}$ for the extraction of four MCs i.e. MC-LR, -LF, -LW, and -LY from a cultured strain of 
Microcystis. The use of a higher percentage of aqueous $\mathrm{MeOH}$ was also recommended by Ramanan et al. [32], which reported that $75 \% \mathrm{MeOH}$ aqueous solution showed higher efficiency for extraction of MC-LR and MC-LA from a cyanobacterial process waste than other solvents. However, as pure $\mathrm{MeOH}$ can be removed more easily than the aqueous MeOH prior to SPE and gives reasonable recoveries for MCs, it was used in this study. In addition, to compensate for the possible low recoveries of MCs using pure $\mathrm{MeOH}$, a large volume was used for extraction to get better recoveries. Under the conditions we used, pure $\mathrm{MeOH}$ performed equally well as $75 \%$ aqueous $\mathrm{MeOH}$, and no detectable MCs were found in cell debris after extraction.

In summary, a simple and cheap cleanup method using silica gel was designed and shown useful to improve the results of analytical and bioanalytical methods for the determination of MCs in different algal samples. By coupling the SPE method to one of the two bioanalytical methods, it is a good alternative to complement the mouse toxicity assay for the screening of MCs.

\section{Acknowledgements}

The authors thank Dr. Y. E. Chang for the instructions in phosphatase assay and $\mathrm{K}$. Thomas for manuscript editing. This work was supported in part by grants (NSC92-2311-B002-103, and NSC91-2323-B002-009 issued to H. N. Chou) from National Science Council, Taiwan.

\section{References}

[1] D.R. de Figueiredo, U.M. Azeiteiro, S.M. Esteves, F.J.M. Gonçalves, M.J. Pereira, Ecotoxicol. Environ. Saf. 59 (2004) 151.

[2] I.R. Falconer, Environ. Toxicol. 14 (1999) 5.

[3] M.G. Antoniou, A.A. de la Cruz, D.D. Dionysiou, J. Environ. Eng. 131 (2005) 1239.

[4] R.M. Dawson, Toxicon 36 (1998) 953.

[5] R. Nishiwaki-Matsushima, T. Ohta, S. Nishiwaki, M. Suganuma, K. Kohyama, T. Ishikawa, W.W. Carmichael, H. Fujiki, J. Cancer Res. Clin. Oncol. 118 (1992) 420.
[6] R.E. Honkanen, J. Zwiller, R.E. Moore, S.L. Daily, B.S. Khatra, M. Dukelow, A.L. Boynton, J. Biol. Chem. 265 (1990) 19401.

[7] D.M. Toivola, J.E. Eriksson, Toxicol. In Vitro 13 (1999) 521.

[8] M. Runnegar, N. Berndt, S.-M. Kong, E.Y.C. Lee, L. Zhang, Biochem. Biophy. Res. Commun. 216 (1995) 162.

[9] I.M. Moreno, R. Molina, A. Jos, Y. Picó, A.M. Cameán, J. Chromatogr. A 1080 (2005) 199.

[10] K. Kaya, T. Sano, H. Inoue, H. Takagi, Anal. Chim. Acta 450 (2001) 73.

[11] J. McElhiney, L.A. Lawton, Toxicol. Appl. Pharmacol. 203 (2005) 219.

[12] M.J. Ruiz, A.M. Cameán, I.M. Moreno, Y. Picó, J. Chromatogr. A 1073 (2005) 257.

[13] A. Cameán, I.M. Moreno, M.J. Ruiz, Y. Picó, Anal. Bioanal. Chem. 380 (2004) 537.

[14] D.L. Campbell, L.A. Lawton, K.A. Beattie, G.A. Codd, Environ. Toxicol. Water Qual. 9 (1994) 71.

[15] C. Vezie, F. Benoufella, K. Sivonen, G. Bertru, A. Laplanch, Phycologia 35 (1996) 198.

[16] T.-H. Lee, Y.-M. Chen, H.-N. Chou, Acta Zool. Taiwan. 10 (1999) 1

[17] B. Sabour, M. Loudiki, B. Oudra, V. Vasconcelos, R. Martins, S. Oubraim, B. Fawzi, Environ. Toxicol. 17 (2002) 24

[18] T. Heresztyn, B.C. Nicholson, Water Res. 35 (2001) 3049.

[19] Y.-M. Chen, R. Huang, H.-N. Chou, J. Food Drug Anal. 13 (2005) 71.

[20] C. Rivasseau, M.-C. Hennion, Anal. Chim. Acta 399 (1999) 75.

[21] J. Rapala, K. Erkomaa, J. Kukkonen, K. Sivonen, K. Lahti, Anal. Chim. Acta 466 (2002) 213.

[22] T.-H. Lee, Y.-M. Chen, H.-N. Chou, Toxicon 36 (1998) 247.

[23] D.J. Finney (Ed.), Probit Analysis, Cambridge, 1971.

[24] H. Mazur, M. Pliński, Oceanologia 43 (2001) 329.

[25] L. Spoof, J. Meriluoto, J. Chromatogr. A 947 (2002) 237.

[26] M. Morohashi, K. Tsuchiya, T. Mita, M. Kawamura, J. Comp. Physiol. B 161 (1991) 69.

[27] N.R. Bury, G.A. Codd, S.E. Wendelaar Bonga, G. Flik, J. Exp. Biol. 201 (1998) 81

[28] L.A. Lawton, C. Edwards, J. Chromatogr. A 912 (2001) 191.

[29] N. Gjølme, H. Utkilen, Phycologia 35 (Suppl. 6) (1996) 80.

[30] J. Fastner, I. Flieger, U. Neumann, Water Res. 32 (1998) 3177.

[31] C.J. Ward, K.A. Beattie, E.Y.C. Lee, G.A. Codd, FEMS Microbiol. Lett. 153 (1997) 465.

[32] S. Ramanan, J. Tang, A. Velayudhan, J. Chromatogr. A 883 (2000) 103. 